\title{
Experimental Investigation of the Equal Channel Forward Extrusion Process
}

\section{Mahmoud Ebrahimi ${ }^{1, *}$, Faramarz Djavanroodi ${ }^{1,2}$, Sobhan Alah Nazari Tiji ${ }^{1}$, Hamed Gholipour ${ }^{1}$ and Ceren Gode ${ }^{3}$}

1 Department of Mechanical Engineering, Iran University of Science and Technology, Tehran 16846-13114, Iran; E-Mails: fdjavanroodi@pmu.edu.sa (F.D.); s.nazari86@yahoo.com (N.T.); h_golipour@yahoo.com (H.G.)

2 Department of Mechanical Engineering, Prince Mohammad Bin Fahd University, Al Khobar 31952, Saudi Arabia

3 School of Denizli Vocational Technology, Program of Machine, Pamukkale University, Denizli 20100, Turkey; E-Mail: cgode@ pau.edu.tr

* Author to whom correspondence should be addressed; E-Mail: mebrahimi@iust.ac.ir; Tel.: +98-914-401-7268.

Academic Editor: Heinz Werner Höppel

Received: 3 February 2015 / Accepted: 3 March 2015 / Published: 16 March 2015

\begin{abstract}
Among all recognized severe plastic deformation techniques, a new method, called the equal channel forward extrusion process, has been experimentally studied. It has been shown that this method has similar characteristics to other severe plastic deformation methods, and the potential of this new method was examined on the mechanical properties of commercial pure aluminum. The results indicate that approximate $121 \%, 56 \%$, and $84 \%$ enhancements, at the yield strength, ultimate tensile strength, and Vickers micro-hardness measurement are, respectively, achieved after the fourth pass, in comparison with the annealed condition. The results of drop weight impact test showed that the increment of $26 \%$ at the impact force, and also decreases of $32 \%, 15 \%$, and $4 \%$ at the deflection, impulse, and absorbed energy, are respectively attained for the fourth pass when compared to the annealed condition. Furthermore, the electron backscatter diffraction examination revealed that the average grain size of the final pass is about $480 \mathrm{~nm}$.
\end{abstract}

Keywords: SPD; ECFE; mechanical properties; impact behavior; grain size 


\section{Introduction}

In the last decade, production and application of ultra-fine grain (UFG) and nano-structure (NS) metals and alloys have been deeply studied by researchers and scientists in the material science field [1,2]. These materials possess improved mechanical properties at the room temperature and enhanced superplastic behavior at higher temperatures [3,4]. In general, there are two main processing categories to fabricate UFG and NS materials, called bottom-up and top-down manners. In the bottom-up method, the UFG or NS materials are synthesized, atom-by-atom, and, also, in layer-by-layer arrangement, and that these samples possess small dimensions with porous structures, which are rarely appropriate for industrial applications. In the top-down approach, micro-structure (MS) materials at the industry scale have been altered to UFG, and even NS ones, using severe plastic deformation (SPD) techniques $[1,5]$.

Up to now, numerous SPD methods have been proposed, experimented, and investigated in detail. Based on the geometry of the work-piece, SPD techniques can be divided into the three groups nominating bulk, sheet, and tube classifications. For group 1: equal channel angular pressing (ECAP) [1], high pressure torsion (HPT) [2], twist extrusion (TE) [6], accumulative back extrusion (ABE) [7]; for group 2: equal channel angular rolling (ECAR) [8], accumulative roll bonding (ARB) [9], constrained groove pressing (CGP) [10]; and for group 3: high pressure tube twisting (HPTT) [11], accumulative spin bonding (ASB) [12], tubular channel angular pressing (TCAP) [13] are the major examples. It should be pointed out that the principal rule of all SPD methods consists of imposing shear stress to the sample, increasing the dislocation density in deformed material, formation of dense dislocation walls and then low angle grain boundaries (LAGBs), and, finally, transformation of LAGBs into high angle grain boundaries (HAGBs) [1,14-17].

Recently, a novel SPD method called the equal channel forward extrusion (ECFE) process has been proposed by authors to fabricate UFG and NS bulk materials [18]. This research focuses on the capabilities of this new method. Hence, mechanical and microstructural investigations have been carried out to observe and compare the characteristics of this new method with the other SPD processes. For this aim, commercial pure aluminum billets have been ECFEed up to four passes and then the potential of this approach has been investigated by means of a tensile test, hardness measurements, an impact test, and microstructural observations.

\section{Principle of the ECFE Process}

The equal channel forward extrusion process is schematically represented in Figure 1a. As can be observed, the ECFE die consists of three major parts: inlet or entry channel, main deformation zone (MDZ), and outlet or exit channel. A sample with a rectangular cross-section is placed in the entry channel and then pushed by punch to pass through the entrance channel and enter the MDZ, where the material is subjected to intense shear stress. As the material passes through the MDZ, the cross-section of the sample incrementally expands in the width direction, and reduces in the length direction, simultaneously. Figure $1 \mathrm{~b}$ represents the alteration of both the length and width of billets' cross-section to each other at the MDZ section, where the area of the rectangular sample remains constant during the process. It needs to be emphasized that there is no sample rotation during the process. 


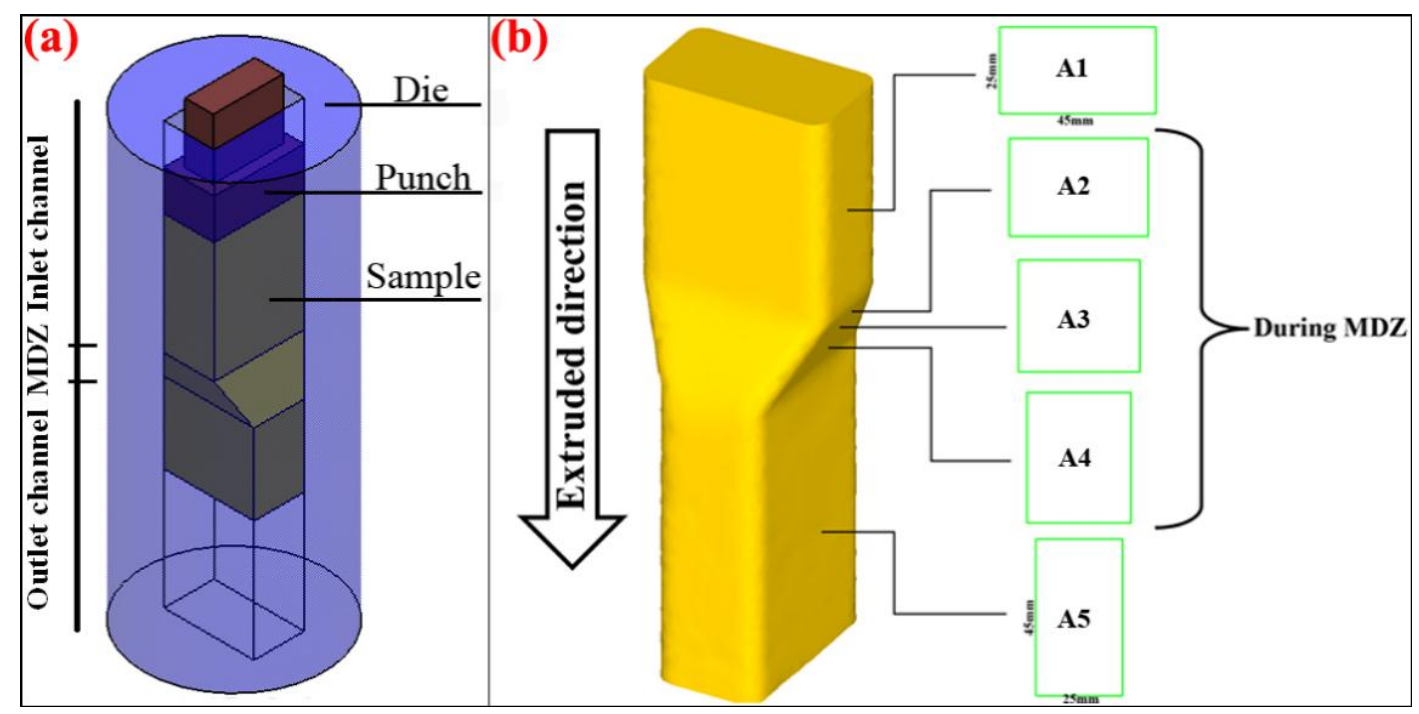

Figure 1. (a) The schematic representation of equal channel forward extrusion process and (b) the length to width alteration at the billet's cross-section in the MDZ section during the ECFE process where $\mathrm{A} 1=\mathrm{A} 2=\mathrm{A} 3=\mathrm{A} 4=\mathrm{A} 5$.

It is noted that the length to width ratio of the sample, and, also, the magnitude of MDZ's height are the two major parameters that influence the strain behavior, mechanical properties, and microstructural characteristics of the deformed materials.

\section{Experimental Procedure}

\subsection{Materials}

Commercial pure (CP) aluminum (A11070) billets with the chemical composition of (in wt.\%) $0.185 \% \mathrm{Fe}, 0.09 \% \mathrm{Si}, 0.012 \% \mathrm{Mg}, 0.011 \% \mathrm{Zn}, 0.008 \% \mathrm{Ti}, 0.008 \% \mathrm{~V}, 0.004 \% \mathrm{Ni}, 0.004 \% \mathrm{Cu}$, $0.003 \% \mathrm{Mn}$, and $\mathrm{Al}$ as the balance, were prepared with the dimensions of $25 \mathrm{~mm} \times 45 \mathrm{~mm} \times 140 \mathrm{~mm}$. Before extrusion, all the samples were annealed at $380{ }^{\circ} \mathrm{C}$ for $1.5 \mathrm{~h}$ and then cooled slowly in a furnace to room temperature $[19,20]$. This leads to a homogeneous and uniform structure with good ductility in all specimens before operation.

\subsection{ECFE Die}

The equal channel forward extrusion set-up, which includes die and punch parts, was designed and manufactured to the following specifications: (1) The die was made of 1.2510 tool steel (hardened up to $50 \mathrm{HRC}$ ) with the channel's cross-section being $25 \mathrm{~mm} \times 45 \mathrm{~mm}$ in the three separate parts, namely entrance channel, MDZ, and exit channel; and (2) The punch was constructed with 1.2344 tool steel (hardened up to 55 HRC). Figure 2 displays the hydraulic press, ECFE die, and CP aluminum samples after extrusion up to the four passes. As can be seen, there is no considerable change in the dimensions of the billet samples after the process. The ECFE process was performed at ambient temperature. Molybdenum disulfide $\left(\mathrm{MoS}_{2}\right)$ was applied as a lubricant to reduce the frictional influence between the die and billet, and, also, the punch speed was equal to $2 \mathrm{~mm} / \mathrm{s}$ during the operation. 


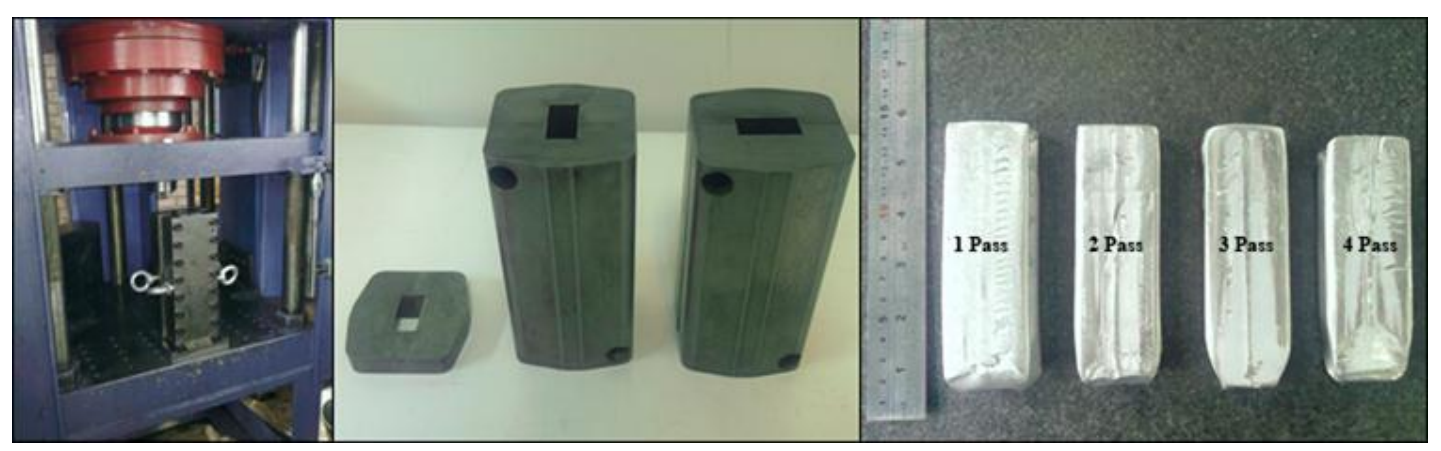

Figure 2. The hydraulic press, ECFE die parts (entrance channel, MDZ and exit channel), and $\mathrm{CP}$ aluminum billets after the ECFE process up to the four passes.

\subsection{Microstructural Testing}

Optical microscopy (OM) was applied by use of Clemex Vision PE software (Clemex, Denizli, Turkey) in accordance with the ASTM E112 to measure the average grain size of the annealed condition. Additionally, the classic Williamson-Hall technique of the X-ray diffraction (XRD, Philips, Tehran, Iran) patterns was employed to theoretically calculate the cell/sub-grain size of the deformed billets. The XRD analysis was conducted on the polished sections of the deformed samples in a Philips X-ray diffractometer, equipped with a graphite monochromator using $\mathrm{CuK} \alpha$ radiation $(1.541 \AA$ ) with an initial angle of $4^{\circ}$, step size of $0.05^{\circ}$, and step time of $3 \mathrm{~s}$. Cell/sub-grain size and lattice distortion are two prominent crystalline imperfections of the materials. These imperfections lead to peak broadening in X-ray diffraction (XRD) patterns [21]. Cell/sub-grain size and lattice micro-strain can be calculated by measuring the deviation of the line profile from the perfect crystal diffraction. In the classic Williamson-Hall technique, cell/sub-grain size of material can be estimated using Equation (1) [22]:

$$
\begin{gathered}
\beta \cos \theta=\frac{k \lambda}{d}+f(\varepsilon) \sin \theta \\
\beta_{\text {exp }}^{2} \cong \beta_{\text {ins }}^{2}+\beta^{2}
\end{gathered}
$$

where, $\beta$ is the integral breadth of the XRD profile, $k$ is the shape factor (0.9), $d$ is the cell/sub-grain size, $\lambda$ is the wavelength, $\varepsilon$ is the lattice strain, $\theta$ is the Bragg angle, and $f(\varepsilon)$ is a defined function. Furthermore, by considering that the experimental profile $\left(\beta_{\exp }\right)$ is the convolution of the instrumental profile $\left(\beta_{\text {ins }}\right)$ and the intrinsic profiles $(\beta)$, the intrinsic profile can be attained by unfolding the experimental profile via the Gaussian assumption, as is represented by Equation (2) [22,23]. Moreover, using Equation (1), a line can be fitted by plotting $\beta \operatorname{Cos} \theta$ against $\operatorname{Sin} \theta$ and the intercept gives the cell size. This line is known as Williamson-Hall graph. Thus, the above equation can be rewritten as:

$$
\left\{\begin{array}{l}
Y=\beta \cos \theta \\
X=\operatorname{Sin} \theta \\
a=f(\varepsilon) \quad \\
b=\frac{0.9 \lambda}{d}
\end{array} \Rightarrow \beta \cos \theta=\frac{0.9 \lambda}{d}+f(\varepsilon) \sin \theta \Rightarrow Y=b+a X\right.
$$

Then, both cell/sub-grain size and strain can be estimated from the y-intercept and the slope of the line, respectively. Figure 3a displays the XRD patterns of the Al1070 after being subjected to one and four 
passes of the ECFE process, respectively. This figure also shows the normalized XRD patterns of the highest intensity peak, indicating the peak shift, which is related to long-range stress, as well as cell/sub-grain boundaries produced by the ECFE process. Furthermore, the grain size of the final pass, at the central portion of billet's cross-section, was measured by electron backscatter diffraction (EBSD) via scanning electron microscopy (SEM) with a field emission (FE) gun, which was operated at an accelerating voltage of $15 \mathrm{kV}$, beam current of $10 \mathrm{nA}$, and step size of $50 \mathrm{~nm}$, using TSL OIM analysis version 5.2 (EDAX, Denizli, Turkey). Prior to the EBSD test, the surface was ground with $\mathrm{SiC}$ paper up to a grit size of 4000 , and then electro-polished in a solution of $100 \mathrm{~mL} \mathrm{HClO}_{4}+900 \mathrm{~mL}$ $\mathrm{CH}_{3} \mathrm{OH}$ at $-20^{\circ} \mathrm{C}$ at a voltage of $50 \mathrm{~V}$.

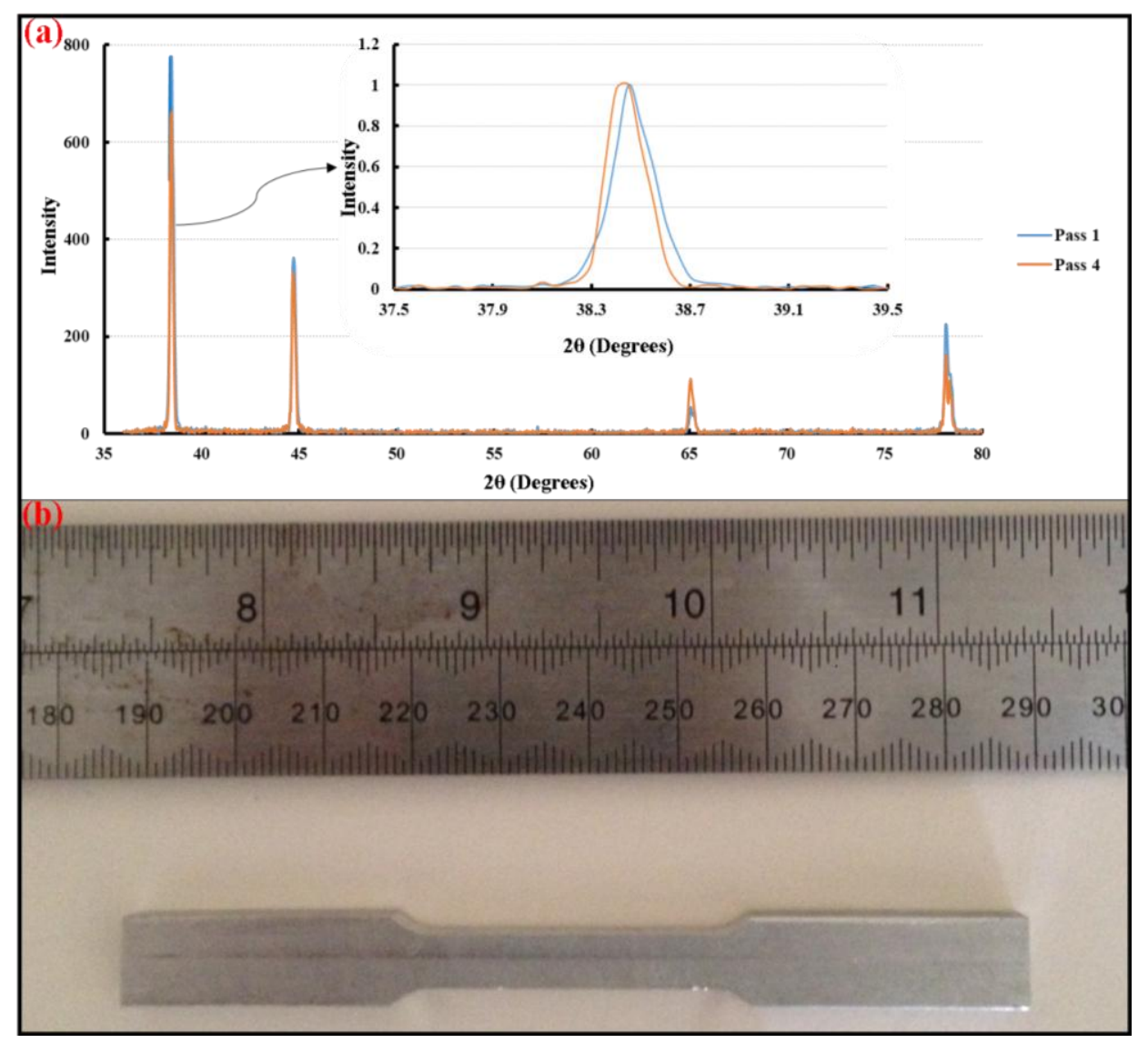

Figure 3. (a) The XRD pattern of the $\mathrm{CP}$ aluminum after the first and fourth passes of the ECFE process and (b) the prepared tensile testing sample of a $\mathrm{CP}$ aluminum billet.

\subsection{Mechanical Testing}

After the extrusion of A11070, up to the four passes, various mechanical and microstructural tests were performed to determine the behavior of $\mathrm{CP}$ aluminum material before and after the process. A tensile test was carried out, according to the ASTM B557M, to obtain yield strength (YS), ultimate tensile strength (UTS), and elongation to failure (El\%). As can be seen in Figure 3b, the gage length, gage width and sample thickness were $25 \mathrm{~mm}, 6 \mathrm{~mm}, 2 \mathrm{~mm}$, respectively. In addition, Vickers micro-hardness (HV) examination was done according to ASTM E92 at the cross-section of the specimens, before and after the ECFE process, to evaluate the hardness properties. The magnitudes of imposed load and dwell time were $100 \mathrm{gf}$ and $15 \mathrm{~s}$, respectively. In order to prepare hardness specimens, 
$\mathrm{SiC}$ paper up to the 1000 grit and afterwards, the $3 \mu \mathrm{m}$ diamond paste were used. HV measurements were performed ten times for each pass sample, and the average magnitude was reported. The wire-cut type of electro-discharge machining (EDM) was used to prepare the tensile test samples.

Moreover, a low velocity drop weight impact test using Instron's Dynatup $9250 \mathrm{HV}$ machine (Instron, Denizli, Turkey) was employed to investigate the influence of the ECFE process on the impact behavior of CP aluminum. During this test, a ball-end dart or tup is raised to a specific height and dropped suddenly on to the test sample, as can be schematically seen in Figure 4. The magnitude of imposed impact energy was constant and equal to $40 \mathrm{~J}$ for all aluminum samples. The shape of the impact tup was a hemisphere with a diameter of $12.5 \mathrm{~mm}$, and, in additiona, a sample with a thickness of $5 \mathrm{~mm}$ was circumferentially clamped using a pneumatic clamp. It was considered to be a fixed-fixed support. The time histories of the impact load and impact velocity were respectively measured and recorded via a load cell and a pair of photoelectric diodes, and the magnitudes of absorbed energy, tup velocity, and deflection at the center were derived and achieved by the use of motion equations [24,25]. These tests were performed to investigate the material grain size refinement, mechanical properties, and impact behavior of $\mathrm{CP}$ aluminum material during the ECFE process.

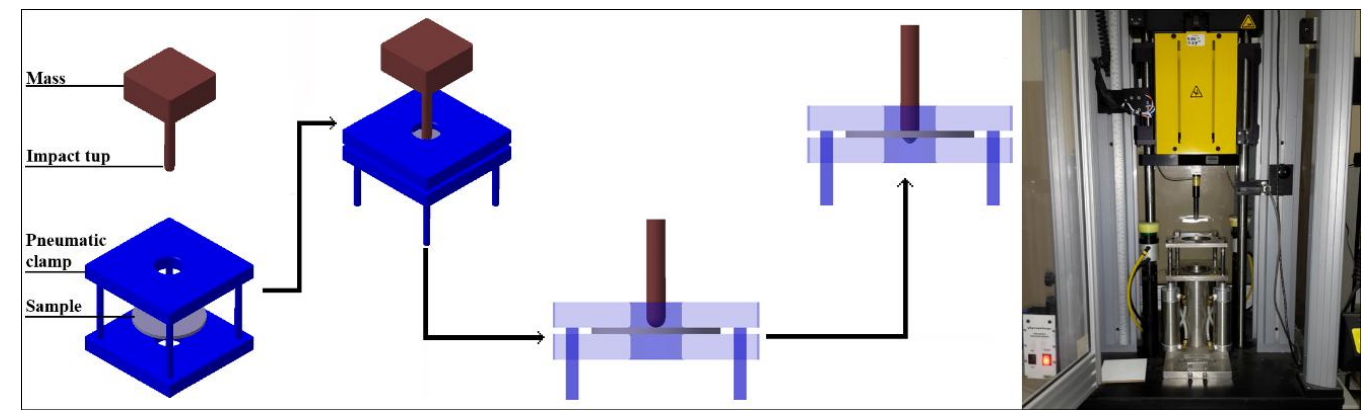

Figure 4. The schematic representation of the drop weight impact test, and, in addition, the used device.

\section{Results and Discussion}

\subsection{Mechanical Properties}

As mentioned above, the ECFE process has been successfully performed on A11070 billets up to four passes. The engineering stress-strain curves of the ECFE aluminum, up to four passes, are presented in Figure 5, and the results including the tensile strengths, elongations to failure, and the magnitudes of hardness measurements, are listed in Table 1 and also shown in Figure 6. By considering Table 1, it can be said that enhancement of the strength values (yield strength (YS) and ultimate tensile strength (UTS)), improvement of the HV magnitudes, and reduction of the elongation percentage were achieved by utilizing this new SPD process. 
Table 1. The mechanical properties and grain size of $\mathrm{CP}$ aluminum billets before and after the ECFE process up to four passes.

\begin{tabular}{cccccc}
\hline $\begin{array}{c}\text { Pass } \\
\text { Number }\end{array}$ & $\begin{array}{c}\text { YS } \\
(\mathbf{M P a})[\mathbf{S D}]\end{array}$ & $\begin{array}{c}\text { UTS } \\
(\mathbf{M P a})[\mathbf{S D}]\end{array}$ & $\begin{array}{c}\text { El } \\
(\%)[S D]\end{array}$ & $\begin{array}{c}\text { HV } \\
\text { [SD] }\end{array}$ & $\begin{array}{c}\text { Cell/sub-grain size } \\
(\mathbf{n m})\end{array}$ \\
\hline 0 & $47[1.63]$ & $78[0.78]$ & $43[0.28]$ & $25[1.05]$ & $\sim 2000$ \\
1 & $84[1.34]$ & $103[0.78]$ & $13.7[0.14]$ & $38[1.82]$ & $\sim 460$ \\
2 & $97[1.70]$ & $109[1.13]$ & $10[0.14]$ & $42[1.37]$ & - \\
3 & $101[1.27]$ & $116[0.56]$ & $8[0.21]$ & $45[1.56]$ & - \\
4 & $104[1.98]$ & $122[0.92]$ & $14.7[0.35]$ & $46[1.63]$ & $\sim 350$ \\
\hline
\end{tabular}

[SD] indicates the magnitude of standard deviation.

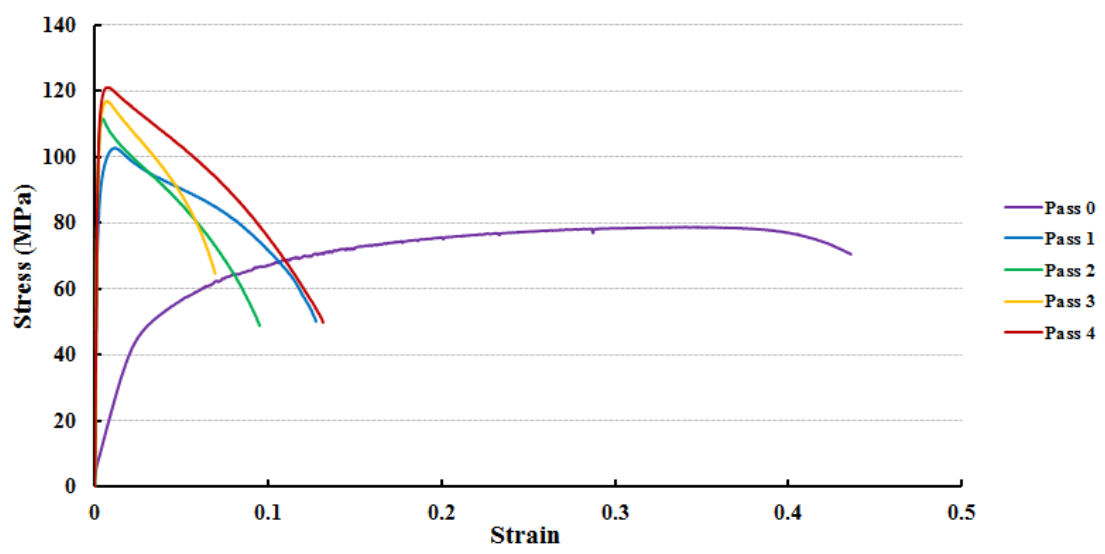

Figure 5. The engineering stress-strain curves for $\mathrm{CP}$ aluminum billets after the ECFE process, up to four passes.

It is obvious that, after the 1st and 4th passes of the ECFE process, 79\% and $121 \%$ enhancements of the YS, $32 \%$ and $56 \%$ improvements of the UTS, and $68 \%$ and $66 \%$ reductions of the El, have been attained as compared to the annealed condition, respectively. In addition, about $52 \%$ and $84 \%$ growths of the HV magnitude were obtained after the first and fourth passes of the process, in comparison with the condition of the as-received materials, respectively. It should be pointed out that the major YS, UTS, and HV increments are achieved after the first pass, and further passes lead to improvements of these properties at a slower rate (see Figure 6). Additionally, Figure 5 shows that the improvement of the yield strength is more profound than the ultimate tensile strength. This means that the uniform plastic area, which is located between the YS and UTS points, has been limited and causes restrictions for various metal forming processes. On the other hand, an intense decrease at the elongation to failure can be seen by imposing the ECFE process. It can be noted that the reduction of the elongation to failure is high after the first pass and then it diminishes at a slower rate. The low magnitude for the elongation to failure property results in a sizeable loss of ductility after the ECFE process. Although the elongation to failure magnitude is increased slightly at the fourth pass, its magnitude is $66 \%$ lower than the aluminum under annealed conditions. The slight increase in the elongation to failure for the fourth-pass ECFE aluminum, as compared to the first pass (7\%) can be related to the occurrence of grain boundary recovery (conversion of LAGBs to HAGBs) [26-28]. This can be due to a decreasing of the internal strains and accumulation of internal energy, therefore, increasing the possibility for crack formation, or it can be related to the increase of the strain rate sensitivity of the material, 
which causes resistance to neck formation. This improvement of the mechanical properties of material behavior using the ECFE process has also been reported for A11050, Al6061, A17075, and nickel during the ECAP process [26,27,29,30] and Al-3\% Mg-0.2\% Sc during the HPT process [31]. In addition, the ECAP process on the same material, reported by Tolaminejad and Dehghani [32], indicated that about $64 \%$ and $108 \%$ enhancement of the hardness value and approximately $202 \%$ and $267 \%$ improvement at the yield strength magnitude have been achieved after the first and fourth passes when compared to the annealed condition. The corresponding percent for the ECFE process is $52 \%$ and $84 \%$ for the $\mathrm{HV}$, and $79 \%$ and $121 \%$ for the YS, respectively.

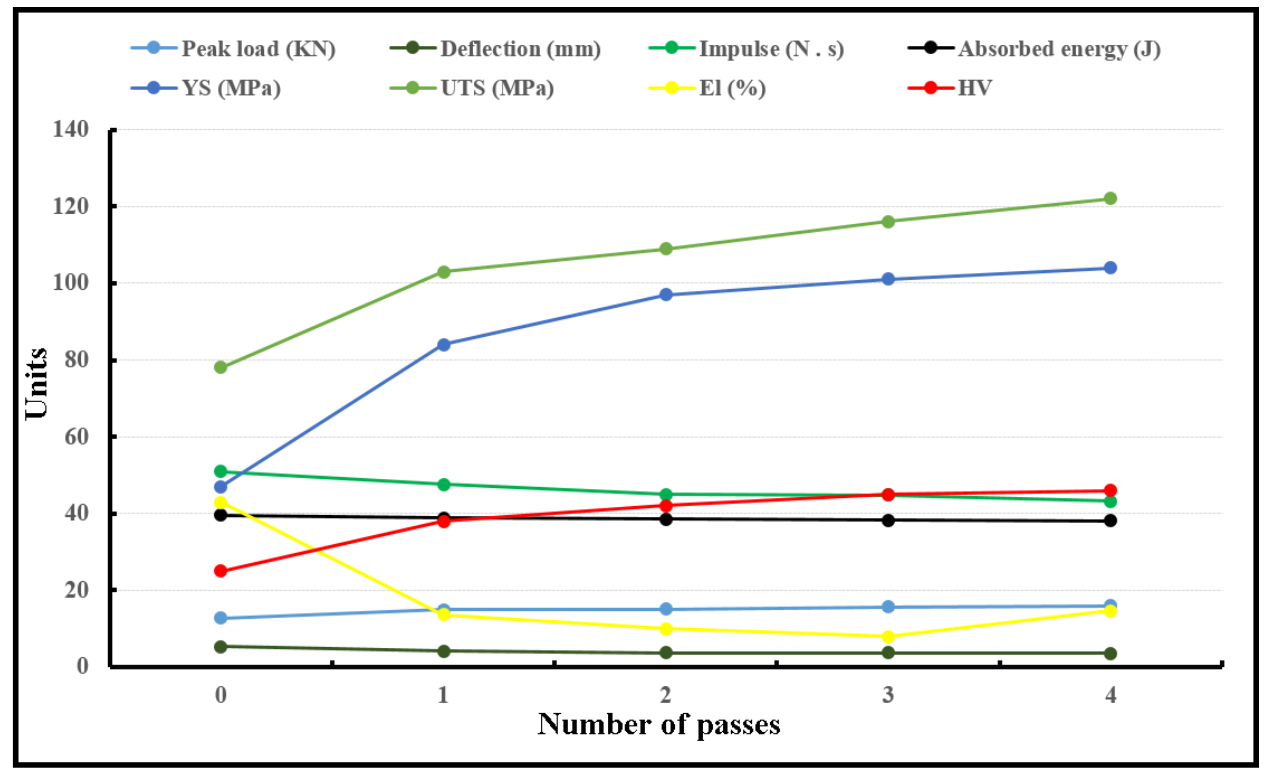

Figure 6. The variation of tensile properties, hardness behaviors, and impact characteristics of the $\mathrm{CP}$ aluminum, before and after the ECFE process, up to four passes.

Low velocity drop weight impact tests have been performed on the $\mathrm{CP}$ aluminum samples before and after the ECFE process to evaluate their impact behavior. Figure 7a,b represent the curves of load versus time and deflection. As seen in this figure, each curve has two regions, including loading and unloading regions. In the first part, the force slowly increases up to the maximum peak load and then it decreases sharply in the second region. The ascending region occurs due to the sample resistance to the impact force, and the descending region is related to the rebound of the tup from the sample. In other words, the required load for penetration is increased when the tup makes contact with the sample's surface. Table 2 lists the magnitudes of peak load, deflection, impulse, and absorbed energy for each pass of the ECFE sample and the trend of impact behavior versus pass number is also shown in Figure 6. The results indicate that the impact load increases and the deflection decreases by adding an ECFE pass number, and that the effects of the first pass ECFE process on the impact behavior is more significant than with other passes. About a $26 \%$ increment of the impact force and also $32 \%, 15 \%$, and $4 \%$ decreases at the deflection, impulse, and absorbed energy, have been obtained, respectively, after the four passes of the ECFE process in comparison with the as-received condition. Thus, it can be said that the highest impact load, and also the lowest deflection, impulse, and absorbed energy can be achieved for the fourth-pass ECFE sample, which means that an aluminum sample with an enhanced strength and brittle behavior has been achieved. These results confirm the obtained tensile properties. 
Interestingly, the smooth slope of the curves of the annealed and first pass samples in Figure $7 \mathrm{~b}$ indicates that the deflection is continued by the same load, which is observed in the ductile materials.

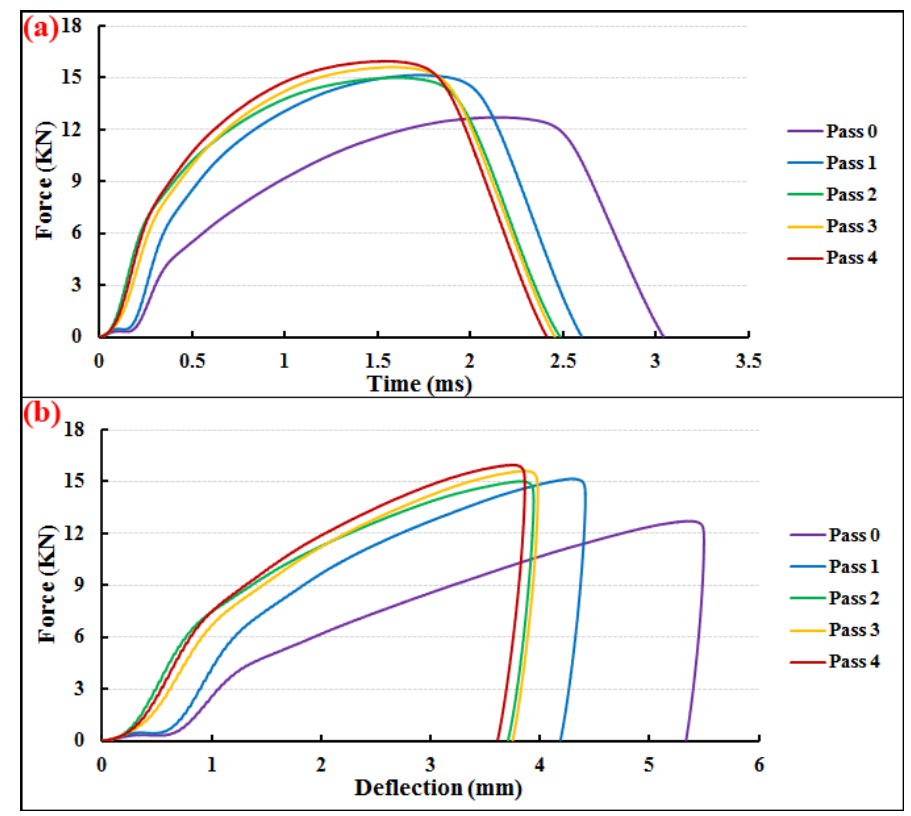

Figure 7. The (a) force-time and (b) force-deflection curves of $\mathrm{CP}$ aluminum billets, before and after the ECFE process, up to four passes, achieved by a drop weight impact test.

Table 2. The impact characteristics of $\mathrm{CP}$ aluminum billets before and after the ECFE process up to the four passes.

\begin{tabular}{ccccc}
\hline $\begin{array}{c}\text { Pass } \\
\text { Number }\end{array}$ & $\begin{array}{c}\text { Peak load } \\
(\mathbf{K N})[\mathbf{S D}]\end{array}$ & $\begin{array}{c}\text { Deflection } \\
(\mathbf{m m})[\mathbf{S D}]\end{array}$ & $\begin{array}{c}\text { Impulse } \\
(\mathbf{N} \cdot \mathbf{s})[\mathbf{S D}]\end{array}$ & $\begin{array}{c}\text { Absorbed energy } \\
(\mathbf{J})[\mathbf{S D}]\end{array}$ \\
\hline 0 & $12.72[0.03]$ & $5.33[0.06]$ & $50.99[0.03]$ & $39.63[0.02]$ \\
1 & $15.03[0.04]$ & $4.19[0.06]$ & $47.64[0.06]$ & $38.92[0.01]$ \\
2 & $15.17[0.06]$ & $3.71[0.01]$ & $45.03[0.02]$ & $38.56[0.02]$ \\
3 & $15.64[0.06]$ & $3.75[0.01]$ & $44.88[0.06]$ & $38.31[0.03]$ \\
4 & $15.98[0.01]$ & $3.61[0.03]$ & $43.30[0.06]$ & $38.16[0.03]$ \\
\hline
\end{tabular}

[SD] indicates the magnitude of standard deviation.

\subsection{Microstructural Characteristics}

The proposed strength mechanism for the SPD materials (modified Hall-Petch relationship) is combined with the contribution of the incidental dislocation boundaries due to the statistical trapping of dislocations (LAGBs) and the geometrically necessary boundaries, because of the difference in the slip system operating with the neighboring slip systems, or local strain differences within each grain (HAGBs) [33]. This superior strengthening behavior is accompanied with a dramatic grain size reduction. Williamson-Hall analyses on the XRD patterns have been used to calculate the crystalline size of the ECFE billets, as can be seen in Figure 3a. Only three high intensity peaks of the XRD patterns of the first and final pass samples have been considered. In addition, optical microscopy (OM) has been employed to measure the average grain size of the as-received aluminum billet. Table 1 lists 
the average grain size of Al1070 before and after the ECFE process for the first and final passes. The results show that the ECFE process results in $77 \%$ and $82 \%$ reductions at the grain size for the 1st and 4th passes of the deformed $\mathrm{CP} \mathrm{Al}$ as compared to the non-ECFE condition. Furthermore, the EBSD orientation color map reveals that the magnitude of the average grain size is about $480 \mathrm{~nm}$ after four passes of the ECFE process, as is represented in Figure 8. Although the calculated XRD method gives the cell or sub-grain size, and the EBSD analysis expresses the average grain size [34], it seems that the results of the EBSD image are more accurate than the theoretical approach because the XRD procedure could be affected by the strain, stress, and energy density and also other relevant parameters influencing the measurement. It is clearly observed that the fraction number of LAGBs is minor and the HAGBs are the major fraction, i.e., the large angle grain boundaries occupy about $87 \%$ of the microstructure. Similar results have been reported for the ECAP process of Al1070, rapid increment of the boundary misorientation angle, and the addition of HAGB fractions up to the four passes [32].

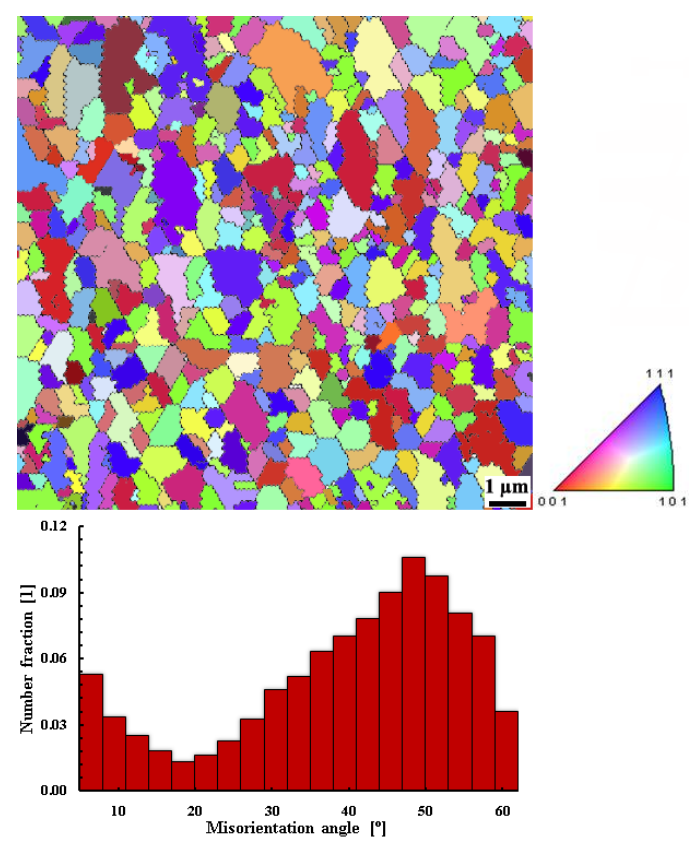

Figure 8. The orientation color map of electron backscatter diffraction for the $\mathrm{CP}$ aluminum billet after the four passes of the ECFE process.

\section{Conclusions}

In this research, the equal channel forward extrusion (ECFE) process had been proposed and introduced as a novel technique of SPD methods to fabricate UFG materials. After designing and manufacturing the die set-up, the capability of this new method has been investigated via tensile test, hardness examination, drop weight impact test, and grain size measurement on commercial pure aluminum billets, which were extruded up to four passes at room temperature. The main conclusions of this research are as follows:

- The magnitudes of yield strength, ultimate tensile strength, and Vickers micro-hardness have increased from $47 \mathrm{MPa}, 78 \mathrm{MPa}$, and $25 \mathrm{HV}$ for the annealed condition to $104 \mathrm{MPa}, 122 \mathrm{MPa}$, and $46 \mathrm{HV}$ for the fourth pass of the ECFE process, which indicate improvements of about 
$121 \%, 56 \%$, and $84 \%$, respectively. In addition, there is about a $66 \%$ reduction at the elongation to failure in this way. Additionally, significant enhancements in the strengthening of $\mathrm{CP}$ aluminum billets was achieved after the first pass of the ECFE process, which is in agreement with the hardness measurements.

- During the drop weight impact test, the magnitudes of peak load, deflection, impulse, and absorbed energy have increased from $12.72 \mathrm{KN}, 5.33 \mathrm{~mm}, 50.99 \mathrm{~N} \cdot \mathrm{s}$, and $39.63 \mathrm{~J}$, to $15.98 \mathrm{KN}$, $3.61 \mathrm{~mm}, 43.3 \mathrm{~N} \cdot \mathrm{s}$, and $38.16 \mathrm{~J}$ after four passes of the ECFE process, which means that material with the enhanced strength and brittle behavior has been attained.

- This superior improvement in the mechanical properties of the ECFE CP aluminum billet is accompanied with grain size reduction. The use of the classic Williamson-Hall method on the XRD patterns indicates that about $77 \%$ and $82 \%$ reductions have been obtained in the cell/sub-grain size of the first and fourth passes of the aluminum billets, in comparison with the annealed condition. Additionally, the EBSD scan of the final pass indicates an average grain size of about $480 \mathrm{~nm}$.

The above outcomes denote that the ECFE process can be a suitable candidate as one of the SPD methods for grain refinement and the production of UFG materials.

\section{Author Contributions}

M. Ebrahimi and F. Djavanroodi were conceived and designed this study. M. Ebrahimi wrote this manuscript and contributed in all activities. The edition was done by F. Djavanroodi. Also, experiments were performed by S.A. Nazari, H. Gholipour and C. Gode. All authors read and approved the manuscript.

\section{Conflicts of Interest}

The authors declare no conflict of interest.

\section{References}

1. Valiev, R.Z.; Langdon, T.G. Principles of equal-channel angular pressing as a processing tool for grain refinement. Prog. Mater. Sci. 2006, 51, 881-981.

2. Zhilyaev, A.P.; Langdon, T.G. Using high-pressure torsion for metal processing: Fundamentals and applications. Prog. Mater. Sci. 2008, 53, 893-979.

3. Kim, W.J.; An, C.W.; Kim, Y.S.; Hong, S.I. Mechanical properties and microstructures of an AZ61 Mg Alloy produced by equal channel angular pressing. Scr. Mater. 2002, 47, 39-44.

4. Sergueeva, A.V.; Stolyarova, V.V.; Valiev, R.Z.; Mukherjee, A.K. Enhanced superplasticity in a Ti-6Al-4V alloy processed by severe plastic deformation. Scr. Mater. 2000, 43, 819-824.

5. Rafizadeh, E.; Mani, A.; Kazeminezhad, M. The effects of intermediate and post-annealing phenomena on the mechanical properties and microstructure of constrained groove pressed copper sheet. Mater. Sci. Eng. A 2009, 515, 162-168.

6. Beygelzimer, Y.; Varyukhin, V.; Synkov, S.; Orlov, D. Useful properties of twist extrusion. Mater. Sci. Eng. A 2009, 503, 14-17. 
7. Kwan, C.C.F.; Wang, Z. Cyclic deformation of ultra-fine grained commercial purity aluminum processed by accumulative roll-bonding. Materials 2013, 6, 3469-3481.

8. Lee, J.C.; Seok, H.K.; Suh, J.Y. Microstructural evolutions of the Al strip prepared by cold rolling and continuous equal channel angular pressing. Acta Mater. 2002, 50, 4005-4019.

9. Saito, Y.; Tsuji, N.; Utsunomiya, H.; Sakai, T.; Hong, R.G. Ultra-fine grained bulk aluminum produced by accumulative roll-bonding (ARB) process. Scr. Mater. 1998, 39, 1221-1227.

10. Shin, D.H.; Park, J.J.; Kim, Y.S.; Park, K.T. Constrained groove pressing and its application to grain refinement of aluminum. Mater. Sci. Eng. A 2002, 328, 98-103.

11. Tóth, L.S.; Arzaghi, M.; Fundenberger, J.J.; Beausir, B.; Bouaziz, O.; Arruffat-Massion, R. Severe plastic deformation of metals by high-pressure tube twisting. Scr. Mater. 2009, 60, 175-177.

12. Mohebbi, M.S.; Akbarzadeh, A. Accumulative spin-bonding (ASB) as a novel SPD process for fabrication of nanostructured tubes. Mater. Sci. Eng. A 2010, 528, 180-188.

13. Faraji, G.; Mashhadi, M.M.; Kim, H.S. Tubular channel angular pressing (TCAP) as a novel severe plastic deformation method for cylindrical tubes. Mater. Lett. 2011, 65, 3009-3012.

14. Xue, Q.; Beyerlein, I.J.; Alexander, D.J.; Gray, G.T. Mechanisms for initial grain refinement in OFHC copper during equal channel angular pressing. Acta Mater. 2007, 55, 655-668.

15. Zhao, G.; Xu, S.; Luan, Y.; Guan, Y.; Lun, N.; Ren, X. Grain refinement mechanism analysis and experimental investigation of equal channel angular pressing for producing pure aluminum ultra-fine grained materials. Mater. Sci. Eng. A 2006, 437, 281-292.

16. Su, C.W.; Lu, L.; Lai, M.O. A model for the grain refinement mechanism in equal channel angular pressing of $\mathrm{Mg}$ alloy from microstructural studies. Mater. Sci. Eng. A 2006, 434, 227-236.

17. Shin, D.H.; Kim, I.; Kim, J.; Park, K.T. Grain refinement mechanism during equal-channel angular pressing of a low-carbon steel. Acta Mater. 2001, 49, 1285-1292.

18. Ebrahimi, M.; Djavanroodi, F. Experimental and numerical analyses of pure copper during ECFE process as a novel severe plastic deformation method. Prog. Nat. Sci. Mater. Inter. 2014, 24, $68-74$.

19. Wang, J.W.; Duan, Q.Q.; Huang, C.X.; Wu, S.D.; Zhang, Z.F. Tensile and compressive deformation behaviors of commercially pure $\mathrm{Al}$ processed by equal-channel angular pressing with different dies. Mater. Sci. Eng. A 2008, 496, 409-416.

20. Reihanian, M.; Ebrahimi, R.; Moshksar, M.M.; Terada, D.; Tsuji, N. Microstructure quantification and correlation with flow stress of ultrafine grained commercially pure Al fabricated by equal channel angular pressing (ECAP). Mater. Charact. 2008, 59, 1312-1323.

21. Mukherjee, P.; Sarkar, A.; Barat, P.; Bandyopadhyay, S.K.; Sen, P.; Chattopadhyay, S.K.; Chatterjee, P.; Chatterjee, S.K.; Mitra, M.K. Deformation characteristics of rolled zirconium alloys: A study by X-ray diffraction line profile analysis. Acta Mater. 2004, 52, 5687-5696.

22. Zhang, Z.; Zhou, F.; Lavernia, E.J. On the analysis of grain size in bulk nanocrystalline materials via X-ray diffraction. Metall. Mater. Trans. A 2003, 34, 1349-1355.

23. Hosseini, E.; Kazeminezhad, M. Nanostructure and mechanical properties of 0-7 strained aluminum by CGP: XRD, TEM and tensile test. Mater. Sci. Eng. A 2009, 526, 219-224. 
24. Múgica, J.I.; Aretxabaleta, L.; Ulacia, I.; Aurrekoetxea, J. Impact characterization of thermoformable fibre metal laminates of 2024-T3 aluminum and AZ31B-H24 magnesium based on self-reinforced polypropylene. Compos. Part A 2014, 61, 67-75.

25. Liu, B.; Villavicencio, R.; Soares, C.G. On the failure criterion of aluminum and steel plates subjected to low-velocity impact by a spherical indenter. Int. J. Mech. Sci. 2014, 80, 1-15.

26. Shokuhfar, A.; Nejadseyfi, O. A comparison of the effects of severe plastic deformation and heat treatment on the tensile properties and impact toughness of aluminum alloy 6061. Mater. Sci. Eng. A 2014, 594, 140-148.

27. Krasilnikov, N.; Lojkowski, W.; Pakiela, Z.; Valiev, R. Tensile strength and ductility of ultra-fine-grained nickel processed by severe plastic deformation. Mater. Sci. Eng. A 2005, 397, 330-337.

28. Bystrzycki, J.; Fraczkiewicz, A.; Lyszkowski, R.; Mondon, M.; Pakiela, Z. Microstructure and tensile behavior of Fe-16Al-based alloy after severe plastic deformation. Intermetallics 2010, 18, 1338-1343.

29. Puertas, I.; Luis Pérez, C.J.; Salcedo, D.; León, J.; Fuertes, J.P.; Luri, R. Design and mechanical property analysis of AA1050 turbine blades manufactured by equal channel angular extrusion and isothermal forging. Mater. Des. 2013, 52, 774-784.

30. Shaeri, M.H.; Salehi, M.T.; Seyyedein, S.H.; Abutalebi, M.R.; Park, J.K. Microstructure and mechanical properties of Al-7075 alloy processed by equal channel angular pressing combined with aging treatment. Mater. Des. 2014, 57, 250-257.

31. Harai, Y.; Edalati, K.; Horita, Z.; Langdon, T.G. Using ring samples to evaluate the processing characteristics in high-pressure torsion. Acta Mater. 2009, 57, 1147-1153.

32. Tolaminejad, B.; Dehghani, K. Microstructural characterization and mechanical properties of nanostructured AA1070 aluminum after equal channel angular extrusion. Mater. Des. 2012, 34, 285-292.

33. Luo, P.; McDonald, D.T.; Xu, W.; Palanisamy, S.; Dargusch, M.S.; Xia, K. A modified Hall-Petch relationship in ultrafine-grained titanium recycled from chips by equal channel angular pressing. Scr. Mater. 2012, 66, 785-788.

34. Azimi, A.; Tutunchilar, S.; Faraji, G.; Besharati Givi, M.K. Mechanical properties and microstructural evolution during multi-pass ECAR of Al1100-O alloy. Mater. Des. 2012, 42, 388-394.

(C) 2015 by the authors; licensee MDPI, Basel, Switzerland. This article is an open access article distributed under the terms and conditions of the Creative Commons Attribution license (http://creativecommons.org/licenses/by/4.0/). 